\title{
A FRAMEWORK FOR MEASURING GEOSPATIAL AMENITY ACCESSIBILITY IN THE PHILIPPINES
}

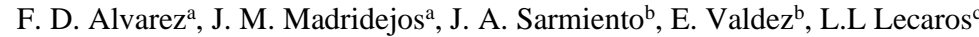

\begin{abstract}
${ }^{a}$ School of Economics, University of the Philippines, Quezon City, Philippines - (fhalvarez@up.edu.ph, jo.madridejos@gmail.com)
${ }^{\mathrm{b}}$ Department of Computer Science, University of the Philippines, Quezon City, Philippines - (jrsarmiento1, efvaldez)@up.edu.ph ${ }^{c}$ Institute of Computer Science, University of the Philippines Los Baños, Philippines - (lordjette.leigh@ gmail.com, lmlecaros@up.edu.ph)
\end{abstract}

KEY WORDS: GIS, geographical accessibility, urban development, amenities, gravitational model, spatial analysis

\begin{abstract}
:
With rapid urbanization, Philippine urban planners and the government face concerns on attaining economic growth and development amidst the growing spatial inequality to social infrastructures, housing imbalances, and inadequate services to urban dwellers. A necessary step to mitigate these issues is to study spatial characteristics with adequate and robust data, which is hardly available in developing countries. In line with this, the paper introduces a framework for measuring geospatial amenity accessibility, using Hansen's gravitation model with the acquired amenities data from OpenStreetMap implemented as Project OHANA (Open-source Heatmap and Analytics for Nationwide Amenities Accessibility in the Philippines). Amenity accessibility findings are discussed for the Philippine regions and disaggregated analysis for the National Capital Region. Validations are made through observations and related literature. To further highlight the applicability of incorporating amenity accessibility data, two use cases were made: (1) on the local government revenue and amenity accessibility relationship, and (2) on concerns to equity of health amenity accessibility across the elderly population. While the findings match with country observations and related literature, the researchers suggest further enhancement of the framework through incorporation of demand and weight factors, and refinements to data inputs and processing to improve the accuracy of analyses.
\end{abstract}

\section{INTRODUCTION}

Urbanization, as how the National Geographic community defines it, is the "process through which cities grow, and higher and higher percentages of the population comes to live in the city." Hence it is often associated to creating positive impacts to economic growth and poverty reduction. Unfortunately, this is not the general truth. For some, economic growth is evident, but poverty reduction results diverge spatially. For countries like China, India, and Vietnam, rural households enjoy the spillovers from urbanization with increase in income levels whereas urban poverty rises (Nguyen, 2012, Cali and Menon, 2013, Zhang, 2016). Moreover, the impact to economic growth depends on rural-urban mobility frictions, supportive policies, and market and infrastructure investments (Turok and McGranahan, 2013).

Rapid urbanization amplifies these concerns. Recognized as one of the fastest urbanizing countries in the East Asia and Pacific Region, the Philippines is predicted to have approximately 102 million people living in cities by the year 2050 (World Bank, 2017). It should be noted that rapid and unregulated urbanization leads to spatial inequality to social infrastructures, housing imbalances, and inadequate services to urban dwellers. Metro Manila is the primary example with rapid growth yet poor urban management as manifested through poor quality housing, overcrowding, inequality of access to essential services and amenities in other areas, and dire traffic conditions (Douglas and Gilbert, 2004). This drives the need to strengthen urban planning and improve access to services and amenities in cities.

An initial and necessary step to urban planning is identifying what the population needs and why they migrate. The primary reasons why people migrate are availability of employment opportunities and accessibility of amenities to the population (Buch et al., 2014, Niedomysl and Hansen, 2010). While there had been works to measure and evaluate spatial accessibility to amenities in other countries (Williams et al., 2019, Di Ciommo, 2018, Cheng et al., 2020), no such extensive applications exist for the Philippines yet. Moreover, the nature of the solutions prevents them from being scalable and granular.

Manual surveying is probably the most heavily used approach in the country. This method requires a huge amount of investments- in forms of time and money - to travel, to set up equipment, to validate results, and so on. This likely leads to insufficient or absence of robust spatial data on land parcels and use. Another hindrance to resolving the challenges to rapid urbanization is the inaccessibility of data to some local government units, coupled with lack of coordination across government agencies (Reyes et al., 2020).

This research introduces a framework for measuring geospatial amenity accessibility which is implemented in Project OHANA (Open-source Heatmap and Analytics for Nationwide Amenities Accessibility in the Philippines) that provides interactive visualizations and data-driven insights in quantifying and measuring accessibility to urban services and amenities across different areas in the country. It uses open-source data from OpenStreetMap to acquire a database of amenities of different categories. The platform allows for overall and amenity typespecific analysis of accessibility as it itemizes which of the amenity categories shall be examined by the analyst. This helps in identifying what type of urban amenities are lacking or overabundant in an area, enabling urban planners and government units in gaining insights from spatial data on amenity availability and accessibility.

The next section details existing literature that tackled measuring accessibility on different areas. Section 3 explains the actual framework implemented from deriving the region of interests to extraction of amenity data, and finally, leading to the calculation of amenity accessibility scores across the Philippines. Section 4 discusses the findings of the calculated scores, specifically in the National Capital Region (NCR), while dissecting each city across different amenity categories. In order to evaluate applicability of using geospatial amenity accessibility scores with different data, Section 5 provides two use cases across NCR, Cebu, and Davao cities. One case is on assessing the relationship of local government revenue and 


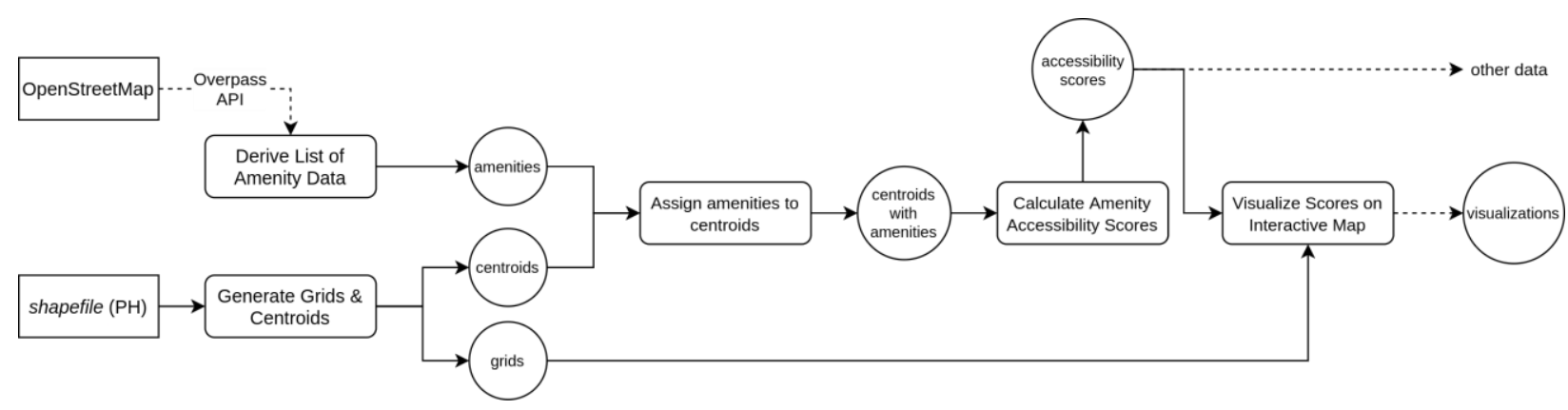

Figure 1: Methodological Framework for Measuring Geospatial Amenity Accessibility

amenity accessibility, and another case on assessing the equality of health amenity accessibility across the elderly population. Section 6 concludes the paper with prospects on future extensions and improvements of the framework.

\section{REVIEW OF RELATED LITERATURE}

A group of researchers from the Massachusetts Institute of Technology (MIT) explored the possibility of collecting data, scraping from Chinese social media open-access API's to develop a computational model to identify areas considered to be ghost cities (Williams et al., 2019). The term is used to describe housing vacancy associated with overdeveloped residential areas accompanied with insufficient amenities around the site. Since 2009, it is known that ghost cities are prevalent in China, however, measuring the extent of this concern is hindered by the country's data restrictions. They utilized Hansen's gravitational model to calculate amenity scores for different locations in the country and based on the idea that thriving communities needing access to basic amenities. The identified potential ghost cities from their model, specifically in Chengdu and Shenyang, were validated through site visits.

So far, the study has only been applied to China, in forms of branched out country case studies. It has not been extended to other countries. The authors believe that such model may be perfectly applied in the case of developing countries with poor data infrastructures and limited resources for regular and/or extensive site visits.

In the case of the Philippines, there is a research exploring spatial accessibility to amenities. They measured multi-criteria-based accessibility scores in Metro Manila, by utilizing a gravity model as well to explore the relationship of accessibility to vehicle ownership and energy consumption (Rith et al., 2020). They collected data from various sources such as Google Maps, the Department of Health (DoH), Department of Education (DepEd), and Commission on Higher Education (CHED). However, seldom do LGUs get specialized data from these agencies, as well as the expertise to process these data collectively. Additionally, the scope is only limited to Metro Manila, and lacks the granularity aspect of measuring accessibility scores from different sizes of zones.

This study attempts to solve these issues on data accessibility and scoping through utilizing a centralized open-source data to measure amenity accessibility. The robustness of the framework is tested through observations and other literature.

\section{METHODOLOGY}

This section discusses the derivation of zones of interests, extraction of amenity data, and calculation of amenity accessibility scores as briefly illustrated in Fig. 1.

\subsection{Amenity Data}

The researchers extracted the list of amenities in the Philippines from OpenStreetMap (OSM), utilizing an Overpass API, to acquire a database of amenities which is divided into six categories: 1) health, including OSM tags of clinic, dentist, hospital, nursing home, pharmacy, and social facility; 2) finance, including atm and bank; 3) education, including school, university, library, kindergarten, and college; 4) security, including fire station and police; 5) transportation, including public transport, station, and fuel; and 6) grocery, including cafe, fast food, restaurant, supermarket, marketplace, and convenience. Two central points were arbitrarily identified, specifically in Itogon municipality of Benguet and in Sipalay city of Negros Oriental, due to API radius limitations. Duplicates and amenities with missing names are dropped to ensure uniqueness and accuracy of the data set respectively.

\subsection{Generating Zones of Interest}

An open-source shapefile map of the Philippine administrative boundaries is divided into multiple grids of equal sizes. Each grid, called zones, have corresponding centroids located at the middle of the grid. For this study, the granularity a zone is $1 \mathrm{~km}$ $\mathrm{x} 1 \mathrm{~km}$. Each zone has information on the municipality or city, region, and province it is located. QGIS is used to generate the grids/zone and centroids data.

Each amenity is assigned to a corresponding centroid as prerequisite for calculating geospatial amenity accessibility score. The assignments are done by finding which centroid is the nearest to the amenity location defined by its longitude and latitude. The distance is defined by the great-circle distance from the amenity to a centroid.

\subsection{Geospatial Amenity Accessibility Score}

The calculation of geospatial amenity accessibility score is derived from Hansen's gravitation model (Hansen, 1959) of spatial accessibility. This has been the foundation of many accessibility measures in the context of transportation costs related to health care (Guagliardo, 2004) and employment (Hess, 2005, Horner, 2004) and many others. Gravity models describe, oftentimes aid predict, spatial flows of commuters, airtravelers, migrants, commodities and even messages (Sen and Smith, 2012). 
The importance of the relative location concept and spatial interaction can be seen in the application and refinement of gravity models over the past fifty years. Its continued use by city planners, transportation analysts, retail location firms, shopping center investors, land developers, and urban social theorists is without precedent. It is one of the earliest models to be applied in the social sciences and continues to be used and extended today.

The reasons for these strong and continuing interests are easy to understand and stem from both theoretical and practical considerations (Haynes and Fotheringham, 2020).

The gravitational-based accessibility model used for this study is:

$$
A_{i}=\sum_{j}^{k} \frac{W}{d_{i, j}^{\beta}}
$$

where

$A_{i}$ is the amenity accessibility score of zone $i$

$W$ is the number of amenities in zone $j$

$k$ is the number of zones within a given maximum study distance

$d_{i, j}$ is the normalized distance from zonei's centroidto zone $j$ 's centroid

In this model, $\beta$ is referred to as the friction coefficient representing the difficulty of travel between zones $i$ and $j$ and can be used as either exponentiation or multiplication (Tóth and Kincses, 2015). Mobility studies typically used a $\beta=1.75$ when determining access to amenities (Williams et al., 2019). For this study, the assigned $\beta$ for the NCR is 2.0.

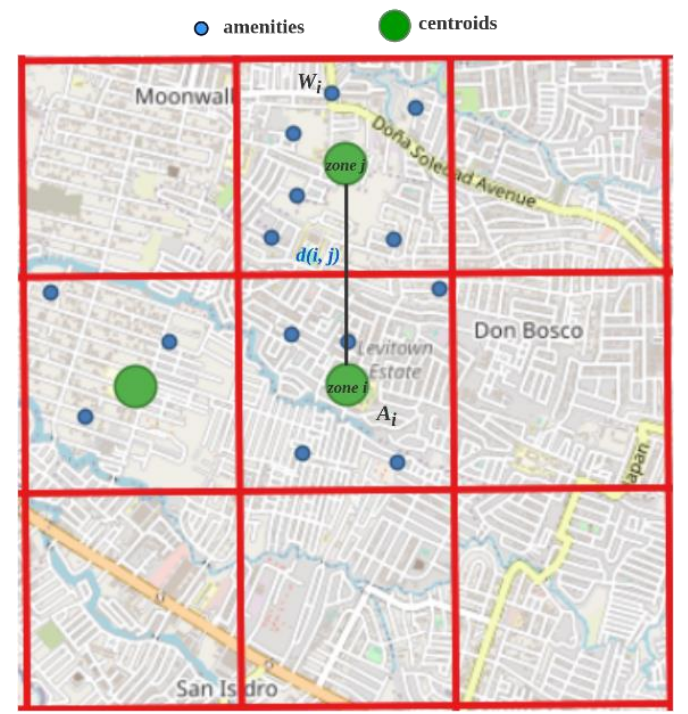

Figure 2: Illustration of Accessibility Score Measurement

The distance $d_{i, j}$ is the calculated great-circle distance between the centroid of each fishnet cell of Zone $i$ and all the other zones within a given arbitrary maximum neighborhood distance (as seen in Fig. 2). For this study, it is set to $14.2 \mathrm{~km}$ radius from Zone $i$ to capture all other zones including centroids in the diagonal. In order to consider the amenities inside the study zone (i.e., when $i=j$ ), a default distance called self-distance is assigned to prevent having zero distance as the denominator. Self-distance is set to $0.5 \mathrm{~km}$.

\subsection{Assumptions and Limitations}

There are three things that should be noted in this model. First is that the current calculations only utilize great-circle distance. This assumption, although too simplified, is based on the idea that a person wishes to travel from point A to destination B at the least distance. Second, the mode of transportation and travel speed is assumed to be fixed and constant respectively. The researchers do not have access and the mechanism yet to capture real time data on expected travel time and distance. Lastly, this study only includes amenities provided by the data from OpenStreetMap. Whether the amenity still exists is still unknown and new establishments may not be included.

\section{RESULTS AND DISCUSSION}

This section discusses the amenity accessibility findings for the entire Philippines, focused analysis of NCR, examination of the different amenity categories, and findings for case studies on local government revenue and amenity accessibility relationship and equity of health amenity accessibility of the elderly population. Both visualizations and data engineering pipeline codes are made available for use in Github respectively. ${ }^{12}$

\subsection{Amenity Accessibility in the Philippines}

The map of the Philippines in Fig. 3 shows the highly saturated accessibility of amenities in NCR, with a score of 814.45, Region IV-A (CALABARZON) ${ }^{3}$ coming in second at 26.97, and Region III (Central Luzon) in third with 18.24. All the other regions depict inaccessibility due to its relatively low average accessibility scores. The Autonomous Region in Muslim Mindanao (ARMM) ranks the least with a score of only 2.43.

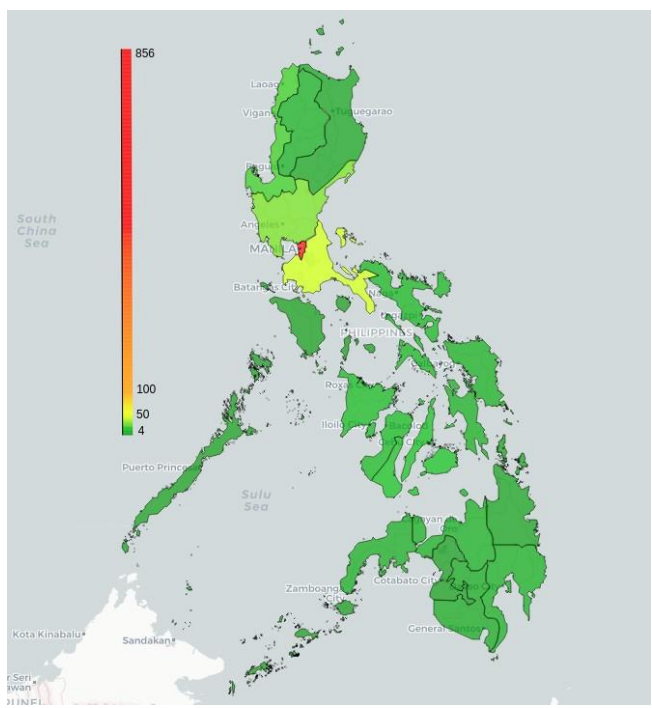

Figure 3: Average Amenity Accessibility Scores per Region in the Philippines

The neighboring regions of NCR, with CALABARZON in its south and Central Luzon in its north, are recognized as key industrial regions which can explain their relatively high amenity accessibility scores. In 2018, these two regions contributed $17.8 \%$ and $9.8 \%$ of the Gross Domestic Product (GDP) respectively, in comparison to NCR which contributed to

${ }^{1}$ https://github.com/lordjette/project_ohana/tree/main/website/te mplates

${ }^{2}$ https://github.com/sarmientoj24/project_ohana

${ }^{3}$ This stands for Cavite, Laguna, Batangas, Rizal, and Quezon. 


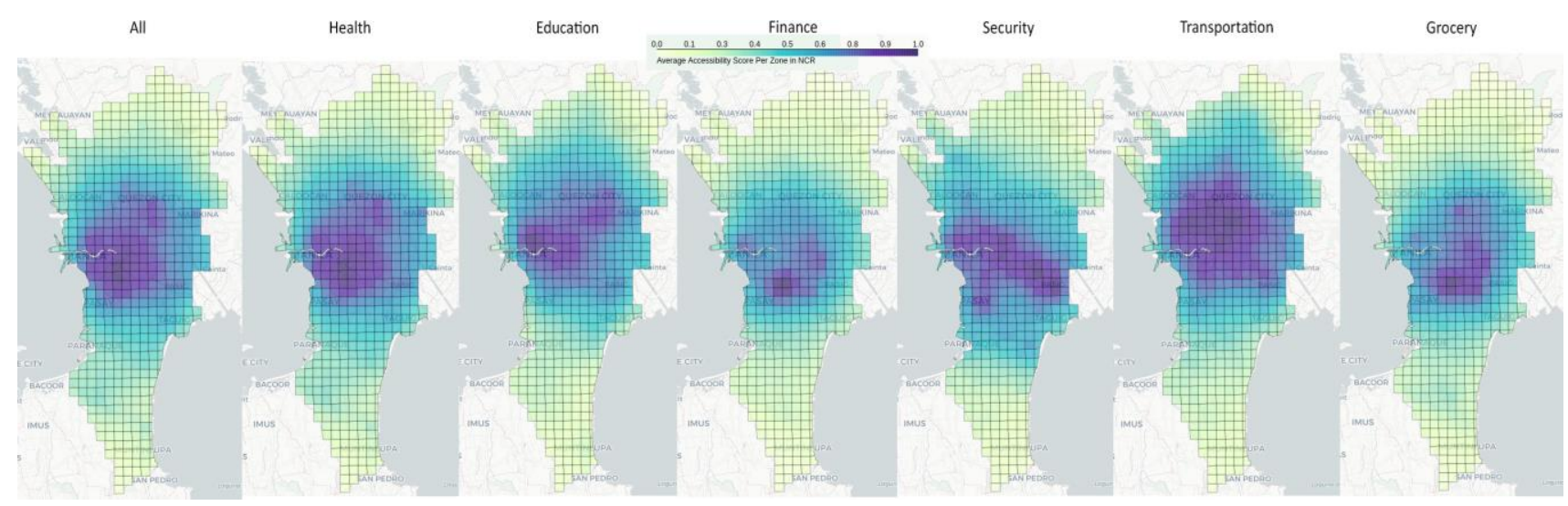

Figure 4: Amenity Accessibility Scores (Normalized) for All Categories in NCR

a third of the country's GDP. In terms of the agriculture, hunting, forestry and fishing (AHFF), industry, and services sectors, these two regions are among the top three major regional contributors (Bangko Sentral ng Pilipinas, 2018). Moreover, this illustrates those areas near, but outside NCR, still have great access to the vast number of amenities in the metro.

This spatial accessibility pattern also reflects the same sentiment of a World Bank Urbanization Review on the overconcentration of development in Metro Manila which is a consequence of an absence of a comprehensive national urban policy. An effective and all-inclusive urban policy is necessary in devising strategies and actions to resolve issues driven by and take advantage of concentration of economic and population growth (World Bank, 2017).

Another lens on which these findings can be scrutinized is through the political factors at play. Strong efforts to decentralize the governmental structure of the Philippines is embodied through the implementation of the Local Government Code of 1991 which gave local government units (LGUs) more authority, responsibilities, and resources. At least in principle, decentralization is expected to strengthen provision of services and resource allocation and bring the government closer to the people. However, a center-periphery relationship between the National Government and LGUs in the country's public finance still emerged. This pattern is also coupled with the inadequacy of the central government in further strengthening decentralization, including fiscal independence and accountability of LGUs (Mendoza and Ocampo, 2017).

Studies have also observed the increasing trend of expenditure responsibilities of these LGUs to the detriment of their revenue powers. In the end, this strengthens their dependence on intergovernmental transfers, specifically on Internal Revenue Allotment of the central government, which contradicts the aim of local independence (Uchimura and Suzuki, 2009, Llanto, 2009, Diokno, 2012). While there are other factors at play, this inadequacy in ensuring decentralization also impacts the delivery of services and development in the grassroots level, especially in the periphery.

\subsection{A Perspective on Amenity Accessibility in NCR}

The amenity-accessibility data also contains different levels of granularity from regional level down to city or even block level. A closer perspective into the locations within NCR in Figure 5 shows that Mandaluyong and San Juan have the highest average accessibility scores. The city of San Juan is recognized as the geometric center of Metro Manila, with Mandaluyong city ad- jacent to its south. Mandaluyong has an advantageous position, with nearby prime cities namely capital city of Manila on the west, Quezon City in its north, Pasig in the east, and Makati in the nearby south. In Makati city alone, there are 83,506 business establishments in 2020 .

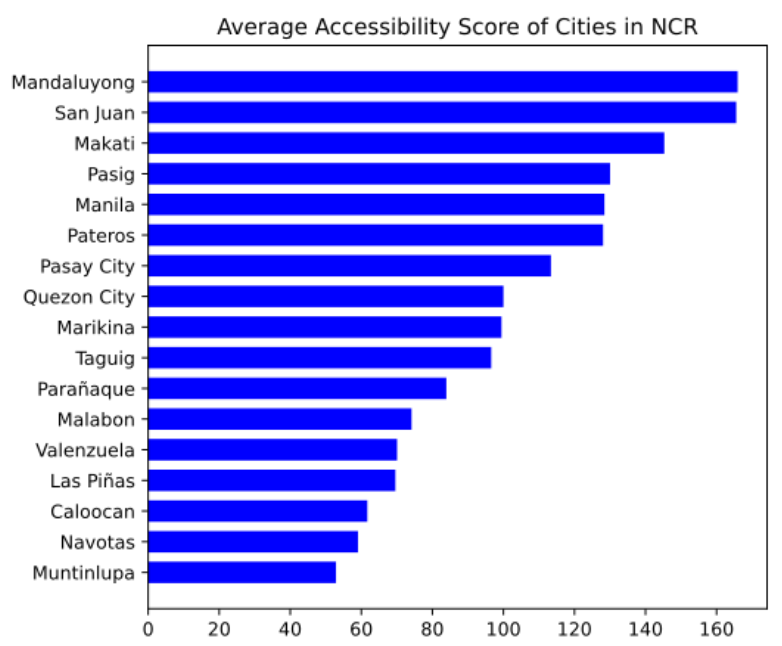

Figure 5: Average Amenity Accessibility Score Per City/Municipality in NCR

It is also currently recognized as the major financial center of the Philippines. As of last year, the city of Manila is recognized as the most competitive Highly Urbanized City (HUC), through the Cities and Municipalities Competitiveness Index (CMCI) (Department of Trade and Industry, 2020). The strategic locations of Mandaluyong and San Juan cities enable access to a plethora of urban services and amenities from its neighboring cities.

On the other hand, Navotas and Muntinlupa are at the bottom two because of their geographic position. Muntinlupa rests at the most southern part of NCR, with its east covered by Laguna de Bay. Navotas is also adjacent to a body of water, specifically Manila Bay, in its west.

\subsection{Dissecting Different Amenity Categories}

The collected data also allows the granularity of deriving amenity accessibility for each of the amenity categories. Figure 4 provides insights on which areas within NCR lack accessibility to certain types of amenities and services. The accessibility scores are normalized between 0 and 1 . As 
expected, all the categories are concentrated within the center, with transportation and health categories covering wider areas in the map with higher average accessibility scores. It is also interesting to observe that the pattern for all amenity types is like the one with only health-related amenities.

For transportation, fuel stations were used as proxy indicators of road and vehicular activities due to limited data availability of public transport in OSM. As of December 2020, a total of 2.9 million motor vehicles in NCR alone, $25 \%$ of the entire Philippines, were registered in the Land Transportation Office (Land Transportation Office, 2020). This plenitude of motor vehicles in Metro Manila can explain the significant abundance of fuel amenities within the area.

Security amenities are also concentrated around Manila. This city garnered the top rank among HUCs in 2020 for Peace and Order, a score component under Government Efficiency of CMCI.

On the other hand, financial amenities have relatively limited scope of accessibility, with only the Makati area showing high concentrations of amenity accessibility. Home to the Central Business District, Makati city has a total of 4,756 banks and financial institutions in 2020.

Rapid and pervasive overconcentration of urbanization and spatial inequality can be detrimental if left uncontrolled. The government, both central and local, should be empowered to institutionalize proper urban planning through the analysis of adequate and robust data to safeguard citizens' health and livelihoods and promote inclusivity and equality of access. The private sector can also use the concentration of amenity types within a particular area as inputs to explore opportune areas for business development or expansion. The academe can also benefit from the use of these data as start-off point in their research and development.

\subsection{Case Studies}

To explore using the framework and the calculated geospatial amenity accessibility scores with data from other sources, this study presents two use cases. Socio-economic data indicators from the Philippine Statistics Authority (PSA) and the Commission on Audit (CoA) are merged into the data.

\subsubsection{Local Government Revenue and Amenity} Accessibility: The first use case explores the relationship between local revenues per capita and overall amenity accessibility across cities in Metro Manila, Davao, and Cebu. It serves to check whether there is a positive or negative correlation between economic activity, which is proxied by local revenues per capita, and amenity accessibility in the localities.

Ideally, the two-way relationship between these variables should be positive. One mechanism could be that the presence of more amenities boosts property values, allowing for more tax collections by concerned LGUs. In turn, upon allocating the budget towards investment-creating projects (i.e., public universities, hospitals, and roads), more urban amenities are built with rise in economic activity. However, this perfect model may not be observed in reality.

First, property values may not actually rise with the presence of more amenities. Spatial scarcity, a combination of accessibility and scarcity, explains the increase or decrease in housing prices (Yuan et al., 2020). Urban amenities can be classified into replaceable and irreplaceable facilities (e.g., high-quality public schools, specialized hospitals). A sole increase in the former may have insignificant effects to housing prices, or even negative, if the urban area is only populated with replaceable amenities. Second, even if property values were to increase and provide budget for public projects, if not allocated properly, may not translate to economic activity gains.

The first instance applies to Metro Manila cities and municipality. Figure 6 clearly shows higher local revenue per capita comes with average accessibility across the cities. The Pearson correlation coefficient is 0.901 with $p=0.070$, revealing that there is a positive significant correlation between the two variables in NCR

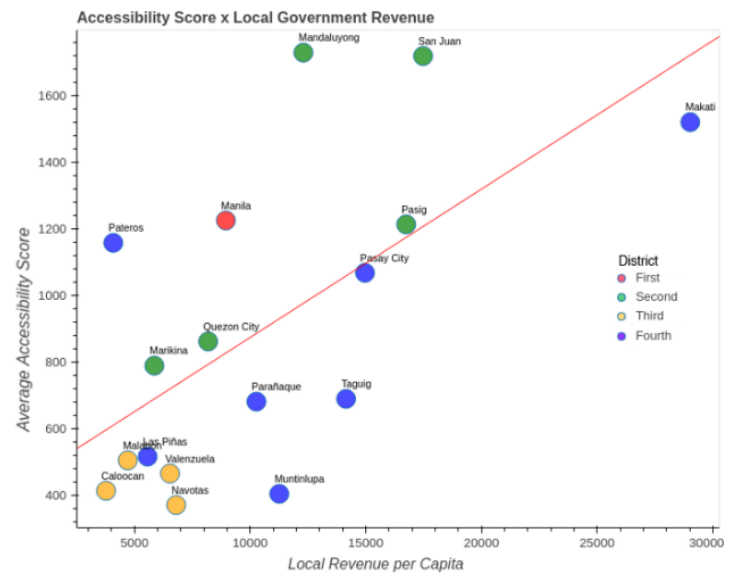

Figure 6: Revenue per capita and Accessibility in the National Capital Region

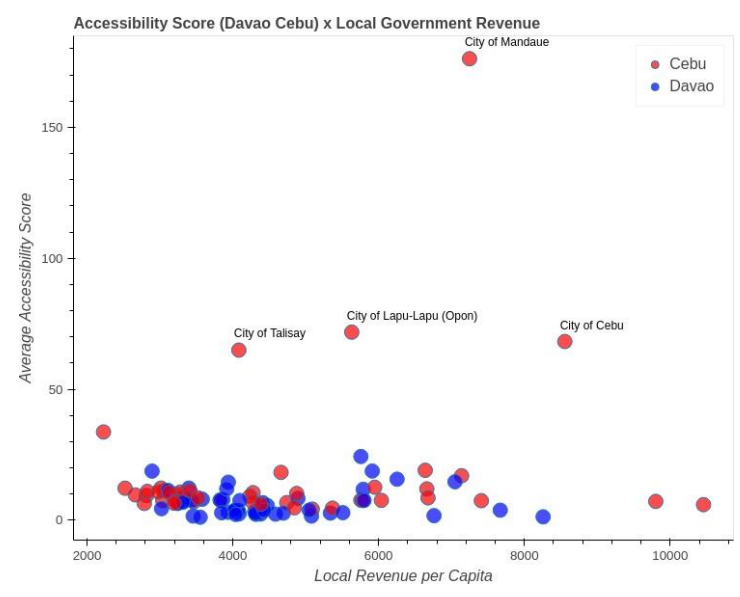

Figure 7: Revenue per capita and Accessibility in the Cebu and Davao Cities/Municipalities

Meanwhile, the second instance applies to Cebu and Davao cities. Figure 7 depicts that the cities crowd to low levels of accessibility despite differences in local revenues. The Spearman correlation coefficient for the entire Cebu province is 0.070 with $p=0.504$, making it appear that local revenue per capita and accessibility are not significantly correlated. Only the cities of Cebu, Mandaue, Lapu-lapu, and Talisay, considered as the province economic hubs due to the presence of several universities and their proximity to Mactan-Cebu International Airport, diverge from the province finding. A lot of people in neighboring towns seek employment in these areas and elsewhere due to city congestion. Hence, in year 2000 , out-migration has proliferated the province (Gonzales, 2004).

4.4.2 Health Amenity Accessibility of the Elderly Population: As the Philippine population grows, the Philippine government faces a challenge for improving health and social services for both the elderly and young population. Being the 
direct stakeholder of this concern, the elderly population had it worse as they are, relatively, physically, and mobilityconstrained individuals. Although grant privileges to senior citizens exist, their awareness does not automatically translate to usage (Cruz et al., 2019). Four major themes related to their unmet needs are financial security, family support, health care services, and age-friendly environment (Carandang et al., 2019).

The second use case focuses on the last two unmet needs, specifically mapping out the uneven spatial distribution to health amenity accessibility of the elder population across the cities of Metro Manila, Davao, and Cebu. Typically, these city centers are hubs to major health facilities. Thus, high levels of health accessibility disparities on specific clusters would mean that the government needs to take action steps or amendments to policies related to its provision of health and social services.

To measure the level of inequality, Gini coefficients are calculated. This indicator was first developed to measure wealth of income inequality. The same principle can be applied to geographical accessibility scores (Cheng et al., 2020). The Gini coefficient ranges from zero, indicating a perfectly equitable distribution of health amenity accessibility, to one, indicating a completely unequal distribution.

The following equation is utilized in this study:

$$
G=\frac{\sum_{i=1}^{n}(2 i-n-1) * x_{i}}{n * \sum_{i=1}^{n} x_{i}}
$$

where

$G$ is the Gini coefficient of the cluster

$n$ is the number of zones in the covered cluster

$x_{i}$ is the product of accessibility score and elderly population density in zone $i$

Note that this is a simplified version from the classical mathematical definition of Gini, making the computation exercise easier and quicker. The equation expects sorted (ascending-order) and non-zero positive values in a onedimensional vector. However, due to observed values (or zones) with zero health accessibility scores, data handling was implemented to ensure that the non-zero value assumption is controlled for.

After computing for this indicator, the findings show that Cebu and Davao have indices higher than the average Gini of the three clusters which is 0.8022 (see Table 1). Spatial inequality in healthcare distribution is prevalent. Cebu and Davao del Sur's result indicate that only few elders have access to a variety of health and social care facilities, whereas most senior citizens residing in the remaining Davao provinces have little to no choice.

\begin{tabular}{|l|c|c|}
\hline Province & Gini Coefficient & Score \\
\hline Cebu & 0.9182 & 3.0602 \\
Davao Oriental & 0.8994 & 0.0376 \\
Davao & 0.8856 & 0.0602 \\
Occidental & & \\
Davao de Oro & 0.8377 & 0.1419 \\
Davao del & 0.8247 & 0.8122 \\
Norte & 0.8106 & 2.8669 \\
Davao del Sur & 0.4392 & 95.2810 \\
NCR & 0.8022 & - \\
\hline Average & & \\
\hline
\end{tabular}

Table 1: Gini Coefficients and Health Accessibility Scores for National Capital Region, Davao Region, and Cebu
Cebu province, garnering a high index of 0.9182 , is dissected into 53 cities or municipalities (see Table 2). The top and bottom five locations are reported in Table 2. Interestingly, the top five reveals low health accessibility scores. Meanwhile, Mandaue city monopolizes the health care facilities in the province and is relatively equal, spatially speaking.

Some zones in thirteen cities/municipalities in Cebu province have zero health amenities. Sogod, the only municipality with completely zero health amenities, showed negative Gini coefficient which reflects the current limitation of the data handling process for zero observed values.

\begin{tabular}{|l|c|c|c|}
\hline Rank & City/Municipality & $\begin{array}{c}\text { Gini } \\
\text { Coefficient }\end{array}$ & Score \\
\hline 1 & Tuburan & 0.9294 & 0.0079 \\
2 & Catmon & 0.7740 & 0.0390 \\
3 & Borbon & 0.7599 & 0.0177 \\
4 & Tabuelan & 0.7331 & 0.0152 \\
5 & Asturias & 0.6856 & 0.1767 \\
$\ldots$ & $\ldots$ & $\ldots$ & $\ldots$ \\
49 & Alcoy & 0.1268 & 0.8268 \\
50 & City of Mandaue & 0.1126 & 41.1798 \\
51 & Alcantara & 0.1049 & 0.3530 \\
52 & Pinamungajan & 0.1029 & 1.0161 \\
53 & Sogod & 0.0000 & 0.0000 \\
\hline
\end{tabular}

Table 2: Top 5 and Bottom 5 Cebu Cities/Municipalities based on Gini Coefficient

On the other hand, NCR garners a low index of 0.4392 (see Table 3). After dissecting, all its cities and municipality depicted a relatively desirable result - high health accessibility scores and low Gini. Individual Gini coefficients tell that health services are equally distributed for the elders.

\begin{tabular}{|l|c|c|}
\hline City/Municipality & Gini Coefficient & Score \\
\hline Caloocan & 0.2312 & 61.6846 \\
Quezon & 0.2303 & 100.0000 \\
Navotas & 0.1733 & 59.0650 \\
Manila & 0.1382 & 128.4333 \\
Marikina & 0.1372 & 99.4528 \\
Valenzuela & 0.1368 & 70.0641 \\
Muntinlupa & 0.1149 & 52.8646 \\
Malabon & 0.1140 & 74.1367 \\
Las Piñas & 0.0850 & 69.5866 \\
Makati & 0.0826 & 145.2812 \\
Taguig & 0.0784 & 96.5713 \\
Pasay & 0.0765 & 113.3762 \\
Parañaque & 0.0711 & 83.9282 \\
Pasig & 0.0521 & 130.0261 \\
Mandaluyong & 0.0243 & 165.9274 \\
Pateros & 0.0153 & 129.0564 \\
San Juan & 0.0151 & 165.5346 \\
\hline
\end{tabular}

Table 3: Gini Coefficients for National Capital Region

\section{CONCLUSION}

Rapid urbanization in the Philippines raises concerns on spatial inequality to social infrastructures and amenity accessibility. It also leads to housing imbalances. Addressing 
this growing problem requires adequate urban planning and development. However, the necessary step to data-driven methodologies and analysis is hampered by a developing country's data limitations. Identification of amenity accessibility inequality is difficult to do amidst the lack of data. The alternative approach which is to find existing studies is also constrained. If such studies do exist, they seldom cater and match the planners' goals. Currently, they do not provide different levels of data granularity to evaluate varying sizes of areas.

Attempting to resolve these issues, this study provides a framework for measuring geospatial amenity accessibility using gravitational models which is implemented in Project OHANA to provide interactive visualizations and data-driven insights in quantifying accessibility to urban services and amenities across different areas in the country. The data is derived from opensource platforms.

Findings in the experiments have shown massive inequality of access throughout the country in favor of the National Capital Region having the highest accessibility to number of amenities within the country. Case studies were also presented to evaluate using the generated scores with other data in an attempt to find correlations and propose a new metric that incorporates the measure of access to urban services.

Future work may explore factoring in demand for the amenities, travel speed to different zones, and assigning different weights to each amenity for developing more robust amenity accessibility scores. Additionally, utilization of database other than OpenStreetMap (i.e., Google Maps API) to include up to date list of amenities is strongly suggested. Since the study also shows the capability of using the generated data and calculated score with other social-economic data, this research paves way to studies that may explore new metrics and a different perspective in urban planning and development.

\section{REFERENCES}

Bangko Sentral ng Pilipinas, 2018. Report on Regional Economic Developments in the Philippines 2018.

Buch, T., Hamann, S., Niebuhr, A. and Rossen, A., 2014. What makes cities attractive? The determinants of urban labour migration in Germany. Urban Studies 51(9), pp. 1960-1978.

Cali, M. and Menon, C., 2013. Does urbanization affect rural poverty? Evidence from Indian districts. The World Bank Economic Review 27(2), pp. 171-201.

Carandang, R. R., Asis, E., Shibanuma, A., Kiriya, J., Murayama, H. and Jimba, M., 2019. Unmet needs and coping mechanisms among community-dwelling senior citizens in the Philippines: a qualitative study. International journal of environmental research and public health 16(19), pp. 3745.

Cheng, L., Yang, M., De Vos, J. and Witlox, F., 2020. Examining geographical accessibility to multi-tier hospital care services for the elderly: A focus on spatial equity. Journal of Transport \& Health 19, pp. 100926.

Commission on Audit. 2020. 2019 Annual Financial Report. Retrieved from https://www.coa.gov.ph/phocadownloadpap/userupload/AnnualFinancial-

Report/lgu/2019/2019_AFR_Local_Govt_Volume_I.pdf.
Cruz, G. T., Natividad, J. N. and Saito, Y., 2019. Activities, social isolation, and information technology. In: G. T. Cruz, C. J. P. Cruz and Y. Saito (eds), Ageing and Health in the Philippines, Economic Research Institute for ASEAN and East Asia, Jakarta, Indonesia, chapter 14, pp. 215-226.

Department of Trade and Industry, 2020. Rankings of highly urbanized cities. data retrieved from Department of Trade and Industry, https://cmci.dti.gov.ph/rankings.php.

Di Ciommo, F., 2018. How the inaccessibility index can improve transport planning and investment.

Diokno, B. E., 2012. Fiscal decentralization after 20 years: What have we learned? where do we go from here? Philippine Review of Economics 49(1), pp. 9-26.

Douglas, I. and Gilbert, A. G., 2004. Urbanization, development and the environment in an unequal world. Routledge.

Gonzales, G. R., 2004. Metro Cebu: A metropolitan area in need of coordinative body. Technical report, PIDS Discussion Paper Series.

Guagliardo, M. F., 2004. Spatial accessibility of primary care: concepts, methods, and challenges. International journal of health geographics $3(1)$, pp. 1-13.

Hansen, W. G., 1959. How accessibility shapes land use. Journal of the American Institute of planners 25(2), pp. 73-76.

Haynes, K. E. and Fotheringham, A. S., 2020. Gravity and spatial interaction models.

Hess, D. B., 2005. Access to employment for adults in poverty in the Buffalo-Niagara region. Urban Studies 42(7), pp. 11771200 .

Horner, M. W., 2004. Spatial dimensions of urban commuting: a review of major issues and their implications for future geographic research. The Professional Geographer 56(2), pp. $160-173$.

Land Transportation Office, 2020.Annual report. data retrieved from Land Transportation Office, https://lto.gov.ph/transparency-seal/annual-reports/file/1167annual-report-2020-as-of-december-2020.html.

Llanto, G. M., 2009. Fiscal decentralization and local finance reforms in the Philippines. Technical report, PIDS Discussion Paper Series.

Mendoza, R. U. and Ocampo, J., 2017. Caught between imperial manila and the provincial dynasties: Towards a new fiscal federalism.

Nguyen, C., 2012. Does urbanization help poverty reduction in rural areas? evidence from a developing country.

Niedomysl, T. and Hansen, H. K., 2010. What matters more for the decision to move: jobs versus amenities. Environment and Planning A 42(7), pp. 1636-1649.

OpenStreetMap. (2021). Data. Retrieved from https://www.openstreetmap.org/.

OpenStreetMap. (2021). Key: Amenity. Retrieved from https://wiki.openstreetmap.org/wiki/Key:amenity. 
Philippine Statistics Authority. 2016. Philippine Population Density (Based on the 2015 Census of Population). Retrieved from https://psa.gov.ph/content/philippine-population-densitybased-2015-census-population.

Philippine Statistics Authority. 2017. Philippine Population Surpassed the 100 Million Mark (Results from the 2015 Census of Population). Retrieved from https://psa.gov.ph/populationand-housing/node/120080.

Reyes, M. R. D., Gamboa, M. A. M. and Rivera, R. R. B., 2020. The Philippines' national urban policy for achieving sustainable, resilient, greener and smarter cities. In: Developing National Urban Policies, Springer, pp. 169-203.

Rith, M., Roquel, K. I. D. Z., Lopez, N. S. A., Fillone, A. M. and Biona, J. B. M. M., 2020. Towards more sustainable transport in metro manila: A case study of household vehicle ownership and energy consumption. Transportation Research Interdisciplinary Perspectives 6, pp. 100163.

Sen, A. and Smith, T. E., 2012. Gravity models of spatial interaction behavior. Springer Science \& Business Media.

Tóth, G. and Kincses, Á., 2015. Accessibility models based on the gravity analogy: In theory and practice. Regional Statistics 5(1), pp. 137-158.

Turok, I. and McGranahan, G., 2013. Urbanization and economic growth: the arguments and evidence for Africa and Asia. Environment and Urbanization 25(2), pp. 465-482.

Uchimura, H. and Suzuki, Y., 2009. Measuring fiscal decentralization in the Philippines.

Williams, S., Xu, W., Tan, S. B., Foster, M. J. and Chen, C.,2019. Ghost cities of China: Identifying urban vacancy through social media data. Cities 94, pp. 275-285.

World Bank, 2017. Philippines Urbanization Review: Fostering Competitive, Sustainable and Inclusive Cities. World Bank Group.

Yuan, F., Wei, Y. D. and Wu, J., 2020. Amenity effects of urban facilities on housing prices in China: Accessibility, scarcity, and urban spaces. Cities 96, pp. 102433.

Zhang, Y., 2016. Urbanization, inequality, and poverty in the people's republic of China. 